\title{
COMPARISON OF MANAGERIAL IMPLICATIONS FOR UTILIZATION OF VARIABLE COSTING AND THROUGHPUT ACCOUNTING METHODS
}

Novak Petr*

Tomas Bata University in Zlín, Faculty of Management and Economics, Zlín, Czech Republic Papadaki Šarka,

Tomas Bata University in Zlín, Faculty of Management and Economics, Zlín, Czech Republic

Hrabec Dušan,

Tomas Bata University in Zlín, Faculty of Management and Economics, Zlín, Czech Republic Popesko Boris,

Tomas Bata University in Zlín, Faculty of Management and Economics, Zlín, Czech Republic

The aim of the paper is to compare the principles, information outputs and consequent managerial implications of the variable costing method and throughput accounting, according to their different perceptions of cost variability. These two approaches could give rise to various product mix decisions and findings relating to effect on profitability. The paper also provides a practical example of limitations experienced on two production lines for certain items. Comparison is made between these two approaches as to which elicits a relevant decision on production mix. Both the variable costing method and throughput accounting represent very similar methods based on variable costs that do not reflect fixed costs. Variable costing methods examine costs that change in accordance with volume of output. On the contrary, throughput accounting merely acknowledges total variable costs, and focuses on limitations which exist in a given company.

Key words: Variable costing, Throughput accounting, TOC, Cost behavior, Cost variability

\section{INTRODUCTION}

Businesses today have to face increasing challenges from competitors relating to time and quality. Competition at an international level has been on the rise, making it ever more necessary for managers to have access to detailed costing information to facilitate effective management. The ability to analyze company costs is one of the most important prerequisites for effective cost management, and it represents an essential indicator of company performance. The most crucial feature of cost analysis is cost classification, i.e. costs are assigned to defined categories according to their given characteristics. Another fundamental aspect is analysis of cost behavior. The relevance of cost information to managerial decision-making has been a central issue in cost accounting for the past 100 years. Decision-making is the most important objective of a cost accounting system. Short-term optimization techniques exemplify a traditional management accounting tool, and are the based on optimization of a product portfolio [04]. According to
Utku et al., three different approaches could be utilized to obtain a product mix decision, these comprising the full costing method, variable costing method, and throughput accounting, the latter of which is based on TOC [28].

The principal aim of this paper is to compare two approaches - throughput accounting and variable costing - and their impact on decisions affecting the structure of production. These methods are very similar in many ways, but instigating them highlights the major impact they make on decisions concerning production structures. This study applies these methods to the same product structure, mainly focusing on the influence of accuracy and details of cost allocation (according to their variability) when judging the prioritization of individual products.

\section{LITERATURE REVIEW}

Throughput accounting (TA) is based on the concepts of TOC and it is implemented in management accounting. This approach is frequently used in organizations which utilizes the Business 
Process Management and other Industrial Engineering tools [27]. Throughput accounting has been designed to inform decisions that boost the profitability of an organization and to accommodate assigning responsibility for those decisions. This is because throughput accounting ensures transparency and visibility of the underlying data and principles on which decision-making rests. In a for-profit corporation, performance measures for TOC are devoted to achieving excellent results in three financial measurements: profit, return on investment (ROI), and cash flow. Goldratt and Cox affirm that if capitalist enterprises are to be evaluated in terms of net profit (NP) and return on investment (ROI), each local action should be judged according to its impact on $\mathrm{NP}$ and ROI. TOC suggests three performance measures in order to achieve this outcome. [11] Throughput is defined as revenue generated by the system through manufacturing sold products (all the money entering the enterprise minus the amount paid to suppliers). Inventory (investment) is considered all financial resources invested in purchasing units that the system intends to sell [16]. Operating expenses are described as nonvariable costs associated with turning said inventory into throughput [18]. The focus of TOC is to maximize throughput and decrease inventory and operating expenses. As TOC primarily concentrates on throughput, the accounting system proposed by TOC is usually referred to as throughput accounting [25]. Goldratt further recommends a fourth measure that may be applied in the context of production mix decisions, the calculation being throughput of an individual product divided by the unit of constraint(s) consumed (Ti/UC) [10]. Variable costing is an inventory costing method that only applies variable production costs to a product; under this method, a fixed factory overhead is not assigned to the product. Typically, variable costs associated with production are direct material costs, direct labor costs, and variable overhead. From a variable costing perspective, fixed costs are generally considered to relate to a period of time, i.e. they are period costs. If, during an accounting period, the given capacity is not fully utilized, then some of the fixed costs represent costs of such idle capacity. Noreen [22] according to Goldratt [10] stated that traditional accounting proved reasonably accurate when direct labor was variable and there were little overheads. However, labor is now often termed a fixed cost and has become a large part of total cost. Simple measurement of the labor output and its distinguishing between variable or fixed cost could not be simply performed [19]. A number of authors claim that TOC is useful only in the short-term, while other accounting methods are more suitable for informing long-term decisions. [12, 15] A serious criticism of the TOC and throughput accounting is that they elicit a short-term view [07], focusing as they do on fixed costs, and they consider variables like price, customer orders, technology and design as fixed [24]. Balderstone and Keef reported that many authors highlight that throughput is defective to the degree that it ignores other variable costs, and the debate on its use is misguided in addition to being based on incorrect specifications. They claim that there may be situations where direct materials are not true variable costs, thus adversely affecting the throughput measure. [01] Louderback and Patterson confirmed that material costs are not merely direct costs, and claim that contribution margin per constraint unit provides a superior solution. [17] Some feel there is little or no difference in throughput and contribution margin [01]. In contrast, studies by Boyd et.al. and Utku et.al. show that taking a TOC-based approach facilitates an optimal solution and generates better profits [04, 18, 28]. Table 1 describes the basic characteristics of direct costing and the theory of constraints.

It is necessary to realize that costs need to be discerned as either variable (linked to load capacity) or fixed (independent of load capacity), because the "Throughput" is represented as sales minus "totally variable" cost (TVC). To offer a definition, TVC equals costs that are only incurred when a product is created. In many instances this means that only direct materials are considered a totally variable cost, though expenditure for subcontracting or custom duties may also apply. For example, direct labor (in most cases) is not totally variable unless employees are only paid if a product is produced [6]. How the Wagner [29] states, in the vast majority of the literature is the issue of variability of costs examined only from the perspective of a relationship quantities for which the volume is considered performance (outputs). Volumes of output as the fundamental cost driver. Indeed, part of such a fixed cost can have a proportional character by maintaining continuity (e.g. costs associated with a charge for production). 
Table 1: Basic characteristics - direct costing, the theory of constraints. [04, 09]

\begin{tabular}{|c|l|}
\hline Cost system & \multicolumn{1}{c|}{ Basic characteristics } \\
\hline & - Fixed overhead is not allocated to products \\
Direct system & - Product costs consist of direct labor, direct material, and the portion of overhead \\
& that varies with the units produced \\
& - Contribution per unit: selling price less direct labor, direct material and variable \\
& - An inventory is understood as an asset \\
\hline & - No concept of product cost \\
Theory of & - Throughput is defined as the price of a unit less the raw material and other costs \\
constraints & that vary for each unit of production (e.g. performance-related pay) \\
& - Throduction are considered an operating expense \\
& - Throughput per unit of the constraint: selling price less raw material cost (or other \\
& - An inventory is understood as a liability that binds money \\
\hline
\end{tabular}

In practice, it is necessary to distinguish between more sets of costs, which could be termed semivariable and semi-fixed costs. The next possibility is to distinguish costs related to a group of products or services. Discussion could continue on such enumeration of variability, for example, through costs, their formation being induced by specific customers and the individual attitude to the same (e.g. in marketing, support from customers, and so on). It is also possible to evaluate the variability of costs in terms of the influence of time. Knowledge of cost behavior is very important, especially for decision-making. As Banker and Byzalov state, understanding cost behavior is a fundamental issue in cost accounting [3]. Uncertainty over demand is likely to affect the commitments of managers regarding "fixed" activity resources, which are selected before actual demand materializes. Banker and Byzalov ask whether firms that face greater uncertainty over demand tend to possess a less rigid cost structure with lower fixed and higher variable costs, or a more rigid cost structure with higher fixed and lower variable costs. Their results, which are not based on absolutely formal analysis of the issue, are contrary to commonly held opinions. [03]

Balakrishnan et al., however, emphasize that virtually every firm has some resources whose adjustment costs are sufficiently large to preclude capacity adjustments in the short-run (e.g., a year, which is the usual time period chosen) [02]. Weiss proposed the following: results indicate that firms with stickier cost behavior obtain less accurate earnings forecasts by analysts than firms with less sticky cost behavior. [30] For each decision taken, the management of a company requires estimates of costs and revenues at different levels of activity for alternative courses of action. Meanwhile the behavior of the costs and any subsequent decision depends on the cost driver. This also highlights Rajnoha or Dejnega, adding that for detailed cost management could be further also use methods such as Activity Based Costing, Time-driven Activity Based Costing, Target Costing, Kaizen Costing and many others, which are based on the detailed calculations according to cost activities and processes $[08,23]$.

\section{METHODS}

The view of cost behavior from the perspective of its variability is crucial for making the managerial decisions. Obviously, it is also essential to apply suitable costing methods and procedures for appropriate cost allocation and prediction.

Conventionally, two different product costing systems are defined - process costing (e.g. via traditional absorption costing) and alternative variable costing. These two major costing approaches differ from one another in the degree of costs assigned to the cost object. A widely utilized method is the traditional absorption fullcosting procedure (job-order costing). Presently, this simple model utilizes overhead rates as costs allocated (most commonly), although this would appear inadequate, as significant inaccuracies arise in the assignment of overhead costs. These inaccuracies can be eliminated by using costing methods based on partial cost absorption, under which costs are allocated as primarily variable or solely direct in nature. 
A number of follow-up surveys have been performed in the past by the authors of this study, which focused on cost management and the utilization of different costing methods adopted by manufacturing enterprises in the Czech Republic. The main objective of this research was to find out how the companies worked with costs - especially overheads, and how they performed their allocation to the various cost objects. The last survey was performed in 2014 as preliminary study for a quantitative part of the research project - "Variability of cost groups and its projection in the costing system in manufacturing enterprises".

This research encouraged the authors to compare two methods that do not allocate all costs to a cost object. The methods chosen are frequently applied so as to aid decision-making on the matter of product mix, the methods in question being variable costing (VC) and throughput accounting (TA).

In order to present the differences between the individual methods that assist decision-making on product mix, it is possible to demonstrate these through providing a model portfolio of four products. Registration took place of the following aspects for each product: the lead time (LT) of two items of production equipment as limiting the input factors, the price of a unit, total variable costs (TVC) - e.g. direct material or subcontracting costs (TVC), and other variable costs (OVC) - e.g. variable labor and variable overhead manufacturing costs $[6,28]$. These costs were also recalculated, by the relative percentages, in relation to the selling price of products. This revealed the degree of share in the price, hence also showed the remainder as a consequence as pertaining to the product. Consequently, it is possible to make various managerial decisions based on this finding.

As can be seen in Table 2, these parameters for individual products differ from each other and it is possible to examine and compare the impact of costing methods specified for managerial decision-making. Furthermore, the process of optimizing the production portfolio was conducted due to the limited overall production time, using the variable costing and throughput accounting methods. It was based on indicators of contribution margin, throughput volume and their share of the limited factor of lead time (LT 1 and LT 2). These indicators determined classification of the benefits of products. Finally, the overall effects were determined (total contribution) resulting from the proposed production mix.

\section{RESULTS}

The survey of the current level of knowledge in this field clearly exposes that constant change and development occur in the business and economic environment; hence companies require new approaches to constantly assess costs and their variability. Apparently, the more precise the determination of the cost variability, the more possible it is, and it supports their recognition by suitable costing methods. Companies very often lack sophisticated tools for proper cost identification and cost allocation, which explains why they are not properly factored into the price of products. Supporters of Activity-Based Costing method espouse that all costs are variable over the long-term. The Activity-Based model captures this variability by assigning costs to products in proportion to the expected long-term demand of each product for costly resources. Nevertheless, there are proponents of the Theory of Constraints, who take a very short-term perspective and assume that the costs of most resources are fixed and inescapable. This means that the TOC model usually only assigns direct material costs or direct labor costs, which are fully variable (performance-related pay) to products while seeking to optimize throughput (i.e. the contribution margin) on the fixed resource capacities that constrain the overall system [20]. From the research carried out, it was found out that companies use calculations pertaining to partial allocation of costs in approximately $25 \%$ of cases. This was also confirmed by recent research, through utilizing the afore-mentioned costing methods, as occurring in $34 \%$ of cases. Consequently, comparison is required of variable costing (VC) and throughput accounting (TA). The following table shows an extension relating to the example of the basic data model (as presented by Novák, Popesko \& Papadaki [21]), thereby demonstrating the major differences in decision-making on various cost allocations. For this example, the authors wish to simply by selecting just four types of products - A, B, C, D, which vary in their method of manufacture, and two production lines - \#1 and \#2. It can be assumed that the manufacturing process differs in length of production time, thus labor content. Additionally, it is presumed that production time is a limiting factor, with 110,000 minutes for production line \#1, and 100,000 minutes for production line \#2. 
Table 2: Default data - lead time, price and costs of products

\begin{tabular}{|l||c|c|c|c|c|}
\hline \multicolumn{1}{|c|}{} & unit & A & B & C & D \\
\hline Lead time (LT) 1 & min per unit & 12 & 20 & 80 & 10 \\
\hline Lead time (LT) 2 & min per unit & 15 & 15 & 90 & 8 \\
\hline Price (P) of unit & CZK per unit & 250 & 400 & 1,200 & 150 \\
\hline $\begin{array}{l}\text { Total variable cost } \\
\text { (TVC) }\end{array}$ & CZK per unit & 110 & 300 & 600 & 30 \\
\hline $\begin{array}{l}\text { Other variable costs } \\
\text { (OVC) }\end{array}$ & CZK per unit & 50 & 40 & 200 & 100 \\
\hline TVC portion (of price) & $\%$ & 44 & 75 & 50 & 20 \\
\hline OVC portion (of price) & $\%$ & 20 & 10 & 17 & 67 \\
\hline
\end{tabular}

${ }^{*}$ TVC = total variable cost (absolute variable cost)

The basis for evaluating the effectiveness of products $A$ to $D$ by using variable costing is determining the contribution margin (c) as the difference between price and variable costs (note: variable cost $\mathrm{VC}=\mathrm{TVC}+\mathrm{OVC}$ ).

$$
\mathrm{C}=\mathrm{P}-\mathrm{VC}
$$

A crucial factor for throughput accounting is the difference between price and totally variable costs (TVC).

$$
\text { tp }=P-T V C
$$

Table 3: Comparison of effectiveness of products

\begin{tabular}{|l|l|l|c|c|c|c|}
\hline & & & A & B & C & D \\
\hline $\mathbf{1}$ & contribution margin (c) & CZK per unit & 90 & 60 & 400 & 20 \\
\hline $\mathbf{2}$ & throughput (tp) & CZK per unit & 140 & 100 & 600 & 120 \\
\hline $\mathbf{3}$ & rank by c & & $2^{\text {nd }}$ & $3^{\text {rd }}$ & $1^{\text {st }}$ & $4^{\text {th }}$ \\
\hline $\mathbf{4}$ & rank by tp & & $2^{\text {nd }}$ & $4^{\text {th }}$ & $1^{\text {st }}$ & $3^{\text {rd }}$ \\
\hline
\end{tabular}

The first option for management decisions is to determine the order of profitability of the products, either according to contribution margin or according to throughput. The table 3 shows that the most profitable product is product $\mathrm{C}$, which shows the highest absolute contribution margin and throughput volume. The second is product $A$, which is similar to $C$. The greatest difference pertains to products $B$ and D. Due to the substantially different other variable costs, the ranking of the products in the methods is reversed. As can be seen, the OVC portion of product $D$ is about $67 \%$ of the price, while it is only $10 \%$ for product $\mathrm{B}$. It is also possible to distinguish totally different values in contribution margin and throughput. In this situation the manager would have to consider, according to which criteria will be for example put products into production process, whether to adhere to the figure of the contribution margin or throughput.

Continuing on, it is necessary to consider which criteria should inform decision-making. Since the products are not equivalent from the viewpoint of labor (lead time), it is desirable to evaluate them based on relative values linked to a limiting fac- tor, therefore comparing:

$$
\text { c/LTi }
$$

and

$\mathrm{tp} / \mathrm{LTi}$

From Table 4, it is evident totally different results are obtained in the relative expression of $\mathrm{c} / \mathrm{LTi}$ and $\mathrm{tp} / \mathrm{LTi}$, which also dramatically alters the order of the products informing such a decisionmaking process. When deciding on product order based on $c / L T_{1}$ or $c / L T_{2}$, it seems the best product would be $A$, and product $D$ the least advantageous. Products $B$ and $C$ are ranked in reverse order. Conversely, according to $t \mathrm{p} / \mathrm{LTi}$, the evaluation is for $D$ as the best product, exactly the opposite compared to assessment following $\mathrm{c} / \mathrm{LTi}$. The least advantageous would then seem to be product $B$ as pertains to $c / L T 1$ or product $A$ in relation to $c / L T_{2}$. Now this begs a question: what do these approaches mean with a view to the overall effect on the company performance? For consideration, there might also be the possibility of production due to market demand (see Table 5, row \#1). The algorithm presented below represents a suitable tool for making a managerial-level decision on the matter of setting both the product and production line mix. 
Table 4: Comparison of relative contribution margin and throughput

\begin{tabular}{|c|l|c|c|c|c||}
\hline & & A & B & C & D \\
\hline $\mathbf{1}$ & c/LT1 & 7.5 & 3.0 & 5.0 & 2.0 \\
\hline $\mathbf{2}$ & c/LT2 & 6.0 & 4.0 & 4.4 & 2.5 \\
\hline $\mathbf{3}$ & tp/LT1 & 11.7 & 5.0 & 7.5 & 12.0 \\
\hline $\mathbf{4}$ & tp/LT2 & 9.3 & 6.7 & 6.7 & 15.0 \\
\hline \hline $\mathbf{5}$ & rank by c/LT1 & $1^{\text {st }}$ & $3^{\text {rd }}$ & $2^{\text {nd }}$ & $4^{\text {th }}$ \\
\hline $\mathbf{6}$ & rank by c/LT2 & $1^{\text {st }}$ & $2^{\text {nd }}$ & $3^{\text {rd }}$ & $4^{\text {th }}$ \\
\hline $\mathbf{7}$ & rank by tp/LT1 & $2^{\text {nd }}$ & $4^{\text {th }}$ & $3^{\text {rd }}$ & $1^{\text {st }}$ \\
\hline \hline $\mathbf{8}$ & rank by tp/LT2 & $4^{\text {th }}$ & $2^{\text {nd }}-3^{\text {rd }}$ & $2^{\text {nd }}-3^{\text {rd }}$ & $1^{\text {st }}$ \\
\hline \hline
\end{tabular}

Algorithm for $\mathrm{VC}$ (contribution margin):

1. Let $\mathrm{i}=1,2$ and $\mathrm{j}=1,2,3,4$. Consider vectors " $c$ " (contribution margin) and "d" (demand) with initial values given by row \#1 in Table 3 and row \#1 in Table 5, respectively. Examine the matrix LT $(i, j)$ given by rows \#1 and \#2 in Table 2. Create a matrix $M$ of size $2 \times 4$, where $M(i, j)$ $=\mathrm{c}(\mathrm{j}) / \mathrm{LT}(\mathrm{i}, \mathrm{j})$, see rows \#1 and \#2 in Table 4. Let $\mathrm{PT}(1)=110,000$ and $\mathrm{PT}(2)=100,000$. Create a vector " $r$ " of size $1 \times 4$.

2. Into vector " $r$ ", substitute the ranking as stated byof the forms of c/LT corresponding to the largest value of each column in $\mathrm{M}$ (see row \#5 in Table 4).

3. Choose and fix the relevant $j$ that has the best ranking in " $r$ " (ranked as "1st"). Choose and fix a row $\mathrm{i}$ (from matrix $\mathrm{M}$ ) with the largest value in column j. Produce as much as possible of the j-th product, i. e. $\min \{d(j), P T(i)$
/ LT(i, j)\} (see rows 2, 3 and 4 in Table 5). If $d(j)>P T(i) / L T(i, j)$, let $M(i, j)=0$, otherwise set $M(1, j)=M(2, j)=0$. Let $P T(i)=P T(i)$ $-\min \{d(j), P T(i) / L T(i, j)\}$ * $L T(i, j)$ and $d(j)=$ $d(j)-\min \{d(j), P T(i) / L T(i, j)\}$.

4. Is the following still true? PT(i)>0. If not, go to step 5 .

5. Is there any remaining unsatisfied demand? If not, go to step 5. Otherwise, return to step 1.Terminate the algorithm.

6. Note: The same algorithm can be applied in the case of throughput by replacing the input data c (with tp) and LT.

The question is, however, which costing method should be used to make a good decision? The following table illustrates the overall contribution of product-production line mix adjusted according to individual methods and criteria.

Table 5: Design of product mix according to variable costing or throughput accounting

\begin{tabular}{|l|l|l|l|l|c|c|c|c|c|}
\hline & & unit & A & B & C & D & Total PT (min) & TCM (CZK) \\
\hline $\mathbf{1}$ & total market demand (d) & pcs & 5,000 & 4,000 & 500 & 8,000 & & \\
\hline $\mathbf{2}$ & production based on c/LT1 & pcs & 5,000 & & 500 & 1,000 & 110,000 & \\
\hline $\mathbf{3}$ & production based on c/LT2 & pcs & & 4,000 & & 5,000 & 100,000 & \\
\hline $\mathbf{4}$ & total production based on c/LT & pcs & 5,000 & 4,000 & 500 & 5,000 & 210,000 & $\mathbf{1 , 0 1 0 , 0 0 0}$ \\
\hline $\mathbf{5}$ & production based on tp/LT1 & pcs & 5,000 & 500 & 500 & & 110,000 & \\
\hline $\mathbf{6}$ & production based on tp/LT2 & pcs & & 2400 & & 8,000 & 100,000 & \\
\hline $\mathbf{7}$ & total production based on tp/LT & pcs & 5,000 & 2900 & 500 & 8,000 & 210,000 & $\mathbf{9 8 4 , 0 0 0}$ \\
\hline
\end{tabular}

* TCM = total contribution margin

In this case, managers would have to decide which products and the amounts of these they should produce as well as which production line should be used to achieve the greatest effect. Rows \#2-7 show a model of setting a product mix based on the order of products from Table 4. In all cases it would be necessary to eliminate part of the production of one product by the maximum possible capacity. In the case of setting production by variable costing (rows \#2 - 4), products $A-C$ are fully included in production, but capability would be limited to producing only 6,000 pieces of product $D$ (although demand outstrips this at 8,000 pieces) $-1,000$ on production line \#1 and 5,000 on production line \#2. Should managers set the product mix based on the order specified by throughput accounting, the decision would be to fully produce 
products $\mathrm{C}, \mathrm{A}$ and $\mathrm{D}$, although product $\mathrm{B}$ would be restricted to 2,900 pieces (compared to a potential 4,000 pieces) - 500 on production line \#1 and 2,400 on production line \#2. The total effect is expressed in the column labeled TCM (total contribution margin). Here it is evident that settling on a product mix based on the order derived from variable costing would bring a greater overall effect in the form of a higher total contribution margin - 1.01 million CZK, compared to 0.984 million CZK resulting from utilizing throughput. Finally, from the above-described comparison of two costing methods - throughput and variable costing, and implementation of optimization steps for the design of product mix, the authors devised an optimization model, one which perfectly suited the issue in question, not excluding similar large-scale problems.

Model for VC Case:

$$
\begin{array}{rlrl}
\max & \sum_{i} \sum_{j} x_{i, j} c_{j} & \\
& & \\
\sum_{j}\left(x_{i, j} t_{i, j} \delta_{i, j}\right) & \leq t t_{i}, & & \forall i, \\
\sum_{i} x_{i, j} & =d_{j}, & & \forall j, \\
\delta_{i, j} d_{j} & \geq x_{i, j} & \forall i, j, \\
\delta_{i, j} & \in\{0,1\}, & \forall i, j, \\
x_{i, j} & \geq 0 & \forall i, j,
\end{array}
$$

with decision variables:

$x_{i, j}:$ amount of a product $\mathrm{j}$ to be produced on production line $\mathrm{i}, x_{i, j} \geq 0$,

$\delta_{i, j}:$ binary variable - if product $\mathrm{j}$ is produced on production line $\mathrm{i}$ or not,

the sets of indices:

$i$ : set of production line, ,

$j \quad: \quad$ set of products

and parameters:

$c_{j}: \quad$ contribution margin, $c_{j}=P_{j}-V C_{j}$ (i.e. price and variable cost),

$d_{j}$ : the demand of product $j$,

$t_{i, j}:$ lead time for production line $\mathrm{i}$ and product $\mathrm{j}$,

$t t_{i}:$ total /maximal) possible lead time for production line $i$.

The authors implemented the model in GAMS software and tested for several suitable modifications to the problem. The model was modified for the variable costing (VC) instance once more. However, replacing cj with tpj meant it could also be applied in the throughput (TP) instance.

\section{DISCUSSION AND CONCLUSION}

Performing analysis and comparison of two given methods could not lead to any general conclusion on or preference for either of the methods. The results of the analysis show the importance of thorough, correct cost allocation and decisionmaking based on relevant information. The example detailed herein clearly demonstrates the significance of casual cost allocation. In the case of throughput accounting, allocation which is limited to direct (totally variable) costs would seem insufficient for effective decision-making. Com- paring two analysed methods, variable method appears more appropriate as it also allocates other variable costs. Despite these disadvantages, however, manufacturing companies often allocate only a small proportion of variable costs - mostly direct material, even when using standard variable costing. The advantage of allocating just direct variable costs is the simplicity involved in assigning merely the cost of direct materials, which tend to be accurately recorded in connection with defined products. Consequently, companies avoid possible inaccuracies that may arise from improper allocation of other cost groups - e.g. allocating salaries in manufacturing. This could represent the core reason for throughput accounting utilizing a throughput indicator (i.e. the price minus totally variable costs), thereby determining the relative amount pertaining to the quoted price of the product, 
which should prove sufficient to cover other costs (other variable costs and overheads). However, as illustrated by the model above, decisions on the basis of throughput accounting could lead to incorrect setting of the product mix. Consequently, a company might well experience diminished profit. Therefore, a significant requirement for proper product mix decisions is thorough, accurate allocation of costs and determination of other variable costs that significantly affect the efficiency of individual products (see other variable costs of product $B$ and $D$ in Table 1).

\section{Other variable cost}

A certain degree of uncertainty in allocating costs that are not considered as totally variable or fixed exists, which goes some way to explaining the frequent absence of assignment of other variable costs. In other words, it is usually unclear how the specific cost groups behave to changes in volume of activity, and how such behavior could be transcribed in accounting entries. For example, labor cost cannot be clearly identified as direct. Would it be worthwhile looking for a link which could describe labor cost as absolutely direct? In fact, only one single case exists where workers were strictly rewarded by piecework pay for labor, which would preclude the possibility of a worker being rewarded at all (even if earning reduced wages), but is also relevant if performance was limited (e.g. due to lack of orders and reduced production at the company). Another problem could arise due to the character of production, where automation and robots work would become a more indirect factor due to actual physical work by employees being replaced by servicing activities - by machine operators. In such cases it is hard to look for a strictly direct relationship to production. Under circumstances like these, such costs can be considered variable, because they correspond to the volume of production, although they cannot be considered as strictly direct. Even more striking is the case of production executives, who do not participate directly in the actual production of individual units - effectively being the masters overseeing production. The same may also be true with other costs which can be classified as other variable cost, such as excipients in production, e.g. lubricants, auxiliary tools, etc. Not least there is also the figure for costs which can be described as "variable production overheads", relating to things such as electricity (for operating factory premises), heating costs, cleaning services, and so on. All of these costs need to be accordingly assigned to their individual performances, which can sometimes be difficult or inaccurate.

Furthermore, as product costing research in Europe shows, a significant proportion of units using a direct labor-based overhead rate (either direct labor cost or direct labor hour rates) or other volume-based overhead rates (e.g. machine hour, material cost, units produced and production time-based rates) have been applied extensively [8]. Many firms are likely to incur overheads driven by direct labor hours, and hence it is not surprising that researchers have found direct labor being used as a basis for assigning overheads to products. However, given the relatively low proportion of product costs that are made up of direct labor costs, it is perhaps surprising to see that it is the most commonly used overhead rate. Simply using a labor-based overhead rate for allocating production overheads can lead to problems relating to inaccurate direct allocation to a unit in the case of automated production.

The matter described above demonstrates that using costing procedures which only allocate absolute direct costs (direct material) for informing the decision-making process is insufficient, revealing the importance of understanding cost behavior and its proper projection in calculation systems. The more detail determined in the variability of costs (as a consequence of various factors and not merely volume of production), the more reliable information one obtains to aid subsequent decisions - on the product mix, pricing of products, production capacity utilization, and so on. Hence, it is apparent that the variability of costs is of utmost importance and indicates the need for further research in this area.

\section{ACKNOWLEDGEMENTS}

This paper is one of the research outputs of the project GA 14-21654P/P403 "Variability of cost groups and its projection in the costing system in manufacturing enterprises" registered at the Czech Science Foundation.

\section{REFERENCES}

1) Balderstone, S. \& Keef, S. (1999). Throughput accounting: exploding an urban myth. Management Accounting (UK), 77, pp. 2628. 
2) Balakrishnan, R., Labro, E., \& Soderstrom, N.S. (2014). Cost structure and Sticky Costs. Journal of management accounting research, 26(2), pp. 91-116.

3) Banker, R. D., \& Byzalov, D. (2014). Asymmetric Cost Behavior. Journal of Management Accounting Research. 26 (2), pp. 4379.

4) Boyd, L. H., \& Cox lii, J. F. (2002). Optimal decision making using cost accounting information. International Journal of Production Research, 40(8), pp. 1879-1898.

5) Brierley, J.A., Cowton, C.J., \& Drury, C. (2001). Research into product costing practice: A European perspective. European Accounting Review, 10, pp. 215-256.

6) Chowdhary, M. (2009). Constraint Management: Throughput, Operating Expenses and Inventory. Global India Publications: New Delhi.

7) Corbett, T. (2003). Throughput accounting and $A B C$ : the driving factors behind each methodology, Journal of Cost Management, (January/February), pp.37-45.

8) Dejnega, O. (2010). Methods Activity Based Costing and Time-Driven Activity Based Costing and their Using in Practice by Measuring Costs of Processes, EMI Economics Management Innovation. Vol. 2, No.1, pp. 11-19.

9) Dugdale, D., \& Jones, T.C. (1998). Theory of Constraints: Transforming Ideas? British Accounting Review. pp. 73-91.

10) 10. Goldratt, E. M. (1990). The Haystack Syndrome: Sifting Information out of the Data Ocean. New York: North River Press.

11) Goldratt, E. M., \& Cox, J. (2004). The Goal: A Process of Ongoing Improvement. Great Barrington: North River Press.

12) Graves, C., \& Gurd, B. (1998). Through-put accounting: a revolution in the making?, Australian CPA, 68 (7), pp. 36-8.

13) Gupta, M., Ko, H.-J., \& Min, H. (2002). TOCbased performance measures and five focusing steps in a job-shop manufacturing environment. Int. J. Prod. Res., 40, pp. 907930.

14) Hansen, Don R., Mowen, M. M., \& Guan, L. (2009). Cost management: accounting \& control. 6th ed. Mason: South-Western.
15) Kee, R., \& Schmidt, C. (2000). A comparative analysis of utilizing activity-based costing and the theory of constraints for making product decisions. International Journal of Production Economics, 63(1), pp. 1-17.

16) Lockamy, A. (2003). A constraint-based framework for strategic cost management. Industrial Management \& Data Systems, 103 (8), pp. 591-599.

17) Louderback, J.G., \& Patterson, J.W. (1996). Theory of constraints versus traditional management accounting. Accounting Education, 1 (2), pp.189-196.

18) Mabin, V.J., \& Balderstone, S. J. (2003). The performance of the theory of constraints methodology: analysis and discussion of successful TOC applications. International Journal of Operations \& Production Management, 23(6), pp. 568-595.

19) Maňák, R., (2015), Statistical Evaluation of the work Performance Factors, International Journal of Entrepreneurial Knowledge, Volume: 3, Issue 1, pp. 32-45

20) Novák, P., \& Popesko, B. (2014). Cost Variability and Cost Behaviour in Manufacturing Enterprises, Economics and Sociology, 7 (4), 89-103. DOI: 10.14254/2071-789X.2014/7$4 / 6$

21) Novák, P., Popesko, B. \& Papadaki, Š. (2015). Comparison of Managerial Implications for Utilization of Variable Costing and Throughput Accounting Methods. Proceedings of the 7th International Scientific Conference Finance and Performance of Firms in Science, Education and Practice. Zlín: Thomas Bata University in Zlín, pp. 1112-1122.

22) Noreen, E., Smith, D., \& Mackey, J.T. (1995). The Theory of Constrains and Its Implication for Management Accounting. North River Press, Great Barrington, MA.

23) Rajnoha, R., \& Dobrovič, J. (2011) Simultánne riadenie ekonomiky a procesov znalst'ou pridanej hodnoty (Simultaneous management of economics and process by value added knowledge). E \& M EKONOMIE A MANAGEMENT, 14 (1), pp. 53-69.

24) Ruhl, J.M. (1997). The theory of constraints within a cost accounting framework, Journal of Cost Management, 11 (6), (November/December), pp.16-24. 
25) Sheu, C., Chen, M.H., \& Kovar, S. (2003). Integrating $\mathrm{ABC}$ and $\mathrm{TOC}$ for better manufacturing decision making, Integrated Manufacturing Systems, 14 (5), pp.433-441.

26) Slávik, Š. \& Bednár, R. (2014). Analysis of Business Models. Journal of competitiveness, 6(4), pp. 19-40

27) Tuček, D., Tučková, Z., \& Hájková, M. (2013), Utilization Level of Business Process Management in Czech Enterprises - Objectives and Factors. $\mathrm{E}+\mathrm{M}$ Ekonomie a Management, 2013, vol. 16, no. 2, pp. 81-98.

28) Utku B. D., Cengiz E., \& Ersoy A. (2011). Comparison of The Theory of Constraints with Traditonal Cost Accounting Methods in Respect to Product Mix Decision. Doğuş Üniversitesi Dergisi, 12 (2) 2011, pp. 317-331.

29) Wagner, J. (2012). Recognition and behavior of variable and fixed costs, Politická ekonomie, 60 (5), pp. $668-678$.

30) Weiss, D. (2010). Cost Behavior and Analysts' Earnings Forecasts. The Accounting Review. 85(4). Pp. 1441-1471.

Paper sent to revision: 09.05.2016.

Paper ready for publication: 13.09.2016. 